\title{
Transformation and Feminisation: The Masculinity of the MBA and the 'Un-development' of Men
}

\author{
Ruth Simpson \\ Professor in Management \\ Brunel Business School \\ Elliot Jaques Building \\ Brunel University \\ Uxbridge \\ UB8 3PH \\ Email: r.simpson@brunel.ac.uk
}

\author{
Afam Ituma, PhD \\ Lecturer, Human Resources Management \\ Brunel Business School \\ Elliot Jaques Building \\ Brunel University \\ Uxbridge \\ UB8 3PH \\ Email: Afam.Ituma@brunel.ac.uk
}




\title{
Transformation and Feminisation: The Masculinity of the MBA and the 'Un-development' of Men
}

\begin{abstract}
Purpose-This paper sets out to explore the gendered nature of the MBA and the benefits men and women gain from the course. In so doing it highlights a relationship between the masculinity of the MBA and the 'un-development' of men.
\end{abstract}

Design/methodology/approach- The paper draws on secondary data and critiques the masculinity of the MBA pedagogy.

Findings- Examining outcomes from the MBA, evidence suggests that while men may achieve greater progress in terms of career development and pay, it is women who are more likely to undergo 'transformational' change.

Originality and value- Drawing on work from critical management education (CME) and on models of learning, this paper argues for the need to 'feminize' the MBA, where feminization is used in a critical context to include a challenge to rather than rejection of dominant discourses. This goes some way to address the charge that, while CME has highlighted some of the programme's moral and political foundations, it has failed to recognise the gendered implications of the MBA.

Article Type: Viewpoint

Key word(s): MBA, masculinity, feminization, learning, transformation 


\section{Transformation and Feminisation: The Masculinity of the MBA and the 'Un-development' of Men}

\section{Introduction}

The continued popularity of the MBA in Northern Europe and the US suggests there are benefits to be gained from the qualification. In support of this, research on MBA outcomes has suggested that graduates benefit from higher salary levels and management status (Catalyst, 2000; Business Week, 2000) with most MBA graduates feeling satisfied with their career progress after the course (Catalyst, 2000). Other work, however, has cast doubt on the role of the MBA in improving organizational effectiveness and performance and has suggested that, by focusing rather narrowly on the functions of management and on 'hard skills' (e.g. Mintzberg and Gosling, 2002; Pfeffer and Fong, 2002), culturally associated with masculinity (Simpson, 1995; 2006; Simpson and Sturges, 2004), the qualification is out of touch with recent developments that encompass a so-called 'feminisation' of management and of careers (Fondas, 1996; Burke and McKeen, 1994). More fundamentally, and from a perspective recently conceptualised as critical management education (Grey, Knights and Willmott, 1996; Grey, 2004), the moral and political foundations of management values and practices have been placed under scrutiny. In this respect, CME has challenged the assumptions and biases within management education, supporting a more reflexive and critical stance. Whilst still marginal within this approach, some writers (e.g. Sinclair, 1995; 2000; Smith, 1997; Simpson, 2006) have accordingly highlighted the masculinity of the MBA by pointing to the attitudes and values of individualism and competitive self-interest, associated with traditional discourses of 
masculinity, as well as to the (masculine) values of managerialism and rationality which underpin many programmes.

In this context, the terms masculinity and femininity are taken to refer to qualities and attributes culturally associated with categories male and female respectively rather than to intrinsic characteristics of men and women (Fondas, 1996). While moving away from essentialist definitions of gender, this division does not disrupt the 'imbalance' between what is considered masculine and feminine or challenge their supposed mutual exclusivity - so preserving and reproducing gender based inequalities (Due Billing and Alvesson, 2000; Knights and Kerfoot, 2004). As Knights and Kerfoot point out, it is difficult to 'dissolve' the gender binary but we can reflect critically on the conditions that privilege the masculine, as the 'dominant centre' (Hearn, 1996), over the feminine and so challenge the former's hegemonic status. The concept of femininity can accordingly be seen in a critical context as a counterpoint and challenge to, rather than complete rejection of, these attitudes and values (Due Billing and Alvesson, 2000). This post-structuralist orientation, rather than seeking to create a new privilege by valorising women's voices and experiences over those of men, challenges the privileging of any voice and so opens up space for critical reflection on the conditions that sustains continued advantage.

Against this background, this paper builds on CME and on theories of learning to explore the masculinity of the MBA and, drawing on recent work on MBA outcomes, how men and women benefit from the course. In so doing, it suggests that while the MBA can be seen to have a masculine bias in terms of course culture, design and underlying values, it is women rather than men who are 'transformed' by the 
experience and who undergo a deeper level of learning. Men by contrast progress through the programme 'un-developed' and largely unchallenged. On this basis, it is argued here that the MBA may be failing men and that a 'critical feminisation' of the MBA, that positions alternative discourses and values, could encourage similar ‘transformations' among aspiring and existing male managers.

The paper is organized as follows. Firstly, the masculine nature of the MBA is explored by acknowledging and moving beyond the more superficial issues of numerical balance (i.e. the continuing low representation of women on MBA courses) and skills (i.e. the 'masculine' nature of skills and knowledge gained) to consider, at a more fundamental level, the values and discourses of masculinity that underpin most programmes as well as some potential factors that shape MBA pedagogy. Secondly, gender differences in MBA outcomes are examined to establish how men and women benefit from the course. The argument is presented that while men gain career benefits of higher pay and managerial status as well as greater marketability, it is women who experience a fundamental shift in their assumptions and values. Thirdly, after linking these 'transformations' to different models of learning, the case is made for a 'critical feminisation' of the MBA to enable a more comfortable environment for women and a richer level of learning for men.

\section{Masculinity of the MBA}

The masculine bias of MBA programmes can be analysed at several levels. At a superficial level, the MBA can be seen to be 'masculine' through the higher proportion of men on most programmes - currently 60-75\% (AMBA, 2004; Catalyst, 2000). Lack of a critical mass of women has been thought to contribute to a 'macho' 
climate that is uncomfortable for many women (Sinclair, 1995) and to the exclusion of their values and interests (Perriton and Reynolds, 2004). Equally, a body of literature has pointed to the focus by many programmes on 'masculine' skills and competencies. In this respect, the MBA has been charged with an overemphasis on 'hard' analytical skills (Pfeffer and Fong, 2002), on quantitatively based techniques (Porter and McKibbin, 1988) and on business functions and analytical approaches to decision making (Minzberg and Gosling, 2002) - largely associated with masculine values and practice (Fondas, 1996; Hines, 1992). Programmes have accordingly been seen as increasingly out of touch with the demands of the modern workplace (Mintzberg and Gosling, 2002; Chia, 1996; Martin and Butler, 2000; Thomson, Maybe, Storey, Gray and Iles, 2000; Weick, Mintzberg and Senge, 1999) in which 'feminine' skills and attributes associated with cooperation, the building of relationships and responsiveness to others (Alvesson, 1998; Kanter, 1989; Lee, 1994) are challenging classical, 'masculine' notions of managerial work.

More fundamentally, the MBA can be seen as masculine in its underlying assumptions and values. In this context, as Grey (2002) suggests the MBA acts as a "purveyor of values" and serves to socialise students into a particular set of morals, ethics and ideals. According to Grey, these are premised to a large extent on discourses of managerialism and rationality. Much of the work exploring the ideological foundations of management education (e.g. Grey, 2002; 2004; Grey and Mitev, 1995; Chia, 1996; Willmott, 1994; Perriton and Reynolds, 2004) has its roots in critical management studies. This perspective problematises the assumed neutrality of management and focuses on management as a moral and political activity that is largely predicated on the search for control (see Alvesson and Willmott, 1992). Critical management education (CME) has 
adopted a similar perspective by critiquing the managerialist assumptions and values within its practices and pedagogies. These assumptions can be seen for example in the functionality inherent in the relationship between management education and management practice. In this respect, as Grey and Mitev (1995) argue, the stated objective of management education is to "contribute to and improve organizational effectiveness and the performance of individual managers" (Grey and Mitev, 1995: 74). CME therefore seeks to uncover the assumptions and biases within that broad aim and to critically evaluate management practice (French and Grey, 1996). Accordingly, it sets out to "reconfigure management education in terms of an attention to values" (Grey, 2004: 182) and to be critically aware of its political and moral significance.

From the perspective of CME, these values are based on the mutually supportive discourses of managerialism and rationality. Managerialist assumptions prevail, not just in the functional relationship that exists between education and practice discussed above, but also in the uncritical supremacy afforded management and its techniques as the solution to diverse organizational problems (French and Grey, 1996; Grey and Mitev, 1995; Watson, 2001) and to the (unproblematised) need for control. Strategic management, for example, may hold the promise that mastery of its practices and techniques will render the future controllable and predictable. As Grey (2004) points out, the promise is false because environmental uncertainties and the unpredictability of human behaviour mean the future is uncertain. Instead, students would be better prepared for the 'real world' by developing skills of flexibility and adaptability as well as an understanding of the impact of decisions on others. 
Values of managerialism, therefore, permeate the MBA. These values coincide with and are largely premised on discourses of rationality. In this respect, an instrumental rationality, based on a calculation of the most efficient means to achieve given ends as characterised in much of the thinking around strategic management, and a technical rationality whereby analysis of techniques (data analysis, change management, financial control) promises order and predictability in organizational outcomes (Clarke, 1999; Roberts, 1996), imbue course content, course culture and design. This can be seen in the assumptions that underlie the curriculum and its delivery as well as in the attitudes of staff and students who display a utilitarian, instrumental approach to knowledge (Grey, 2002; Roberts, 1996) and a competitive and individualistic stance towards course content and course activities (Alvesson and Willmott, 1992; Sinclair, 1995; Cunliffe, Foray and Knights, 2002). Roberts (1996), for example, points to the emphasis on examinations as evidence of dominant discourses of instrumentalism, competitiveness and hierarchy within programmes which work against interdependence and the skills of practical engagement. Similarly, Beatty (2004) draws parallels between the language of economics (inflation, averages, competition, failure) and the instrumental focus on grading in management education which, she argues, distracts us and our students from "intrinsic and non-quantifiable goals such as personal development and the importance of relationships in teaching and learning" (P 187).

In adopting a critical approach, CME therefore explores the moral and political nature of the values underpinning management education. In particular it highlights the ways in which discourses of managerialism and (instrumental, technical) rationality infuse course content, course design and assessment strategies. However, as Simpson (2006) 
and Perriton and Reynolds (2004) argue, CME has largely failed to recognise the gendered nature of those assumptions and their implications for the experiences of men and women who embark on such programmes. While there is a growing body of work that is engaged in a critical scrutiny of the masculinity of management (e.g. Hearn, 1994; Collinson and Hearn, 1994; Alvesson, 1998; Knights and McCabe, 2001), less attention has been paid, even within the field of CME, to masculine ideologies that support the MBA.

In this respect, masculine discourses are closely aligned with preoccupations around direction and control (Connell, 1995; 2000; Hearn, 1994) and have been shown to coincide with values and assumptions within both managerialism (e.g. Collinson and Hearn, 1994; Kerfoot and Whitehead, 1998; Kerfoot and Knights 1993; 1998) and rationality (Ross-Smith and Kornberger, 2004; Morgan, 1996). Managerialist initiatives such as performance reviews and performance targets have been linked to a 'compulsive masculinity' (Kerfoot and Knights, 1993) through the quest for power and control and the continuous pursuit of targets and challenges (e.g. Kerfoot and Knights, 1993; 1998; Hearn, 1994). As Brooks and Mackinnon (2001) argue, gendered activities and gendered values are involved in the drive to achieve corporate objectives through managerialist processes such as codification, judgement, measurement and discipline - all of which conform with activities and attributes which are seen to be dominantly male (Connell, 2000). Discursive practices and assumptions that underpin the rationale and performance of managerialism are therefore heavily gendered and converge with masculinity in the preoccupation with power, accountability and control. 
Similarly, rationality, largely predicated on the exclusion of the feminine, has close connections with qualities considered masculine such as efficiency, effectiveness and calculating self interest (Morgan, 1996; Knights and McNabe, 2001). Technical rationality for example conforms with masculinity both in the gendered engineering metaphor that forms its roots and in the value placed on the mastery of techniques as the means of achieving managerial control. By the same token, instrumental rationality, based on the identification of the most efficient means to achieve given ends, is quintessentially male in the emphasis given to monetary calculations for determining the most effective, most efficient means for realising one's material self interest. As Bologh (1990), cited in Ross-Smith and Kornberger (2004), argues, this process:

“implies reliance on precise measurements, comparison and quantitative calculation of costs and benefits ...Instrumental calculating rationality brings with it qualities considered masculine: smart and decisive self-determination or free, confident aggressive action" Bologh (1990: 126)

Managerialism and rationality, as powerful discourses that underpin both management itself and management education, cannot therefore be seen to be gender free but are closely aligned with values associated with dominant notions of masculinity. These values potentially can override the implications of numerical imbalance or the relative focus on 'hard' or 'soft' skills. In this respect, a greater proportion of women on programmes or an orientation towards more 'feminine' skills of personal and interpersonal development are unlikely on their own to alter in any fundamental way the underlying (masculine) ethos of the course. Research suggests that the masculine orientation of the MBA is one of the key factors that discourage women from enrolling in MBA programmes. Kilduff and Mehra(1996) for instance, found that 
female MBA student usually experience incongruence between gender identity and managerial model promoted by business schools in the sense that they find themselves having to act like 'surrogate men'(p.118).

This masculine orientation may be driven by several factors. As Currie and Knights (2003) argue, it is organisational needs and their notion of relevant skills that give the MBA its currency. In this respect, notions of the 'ideal' manager (Schein, 2001) together with the requirements of the business world, oriented around a purposive rationality and competitiveness (Sinclair, 1995; Kerfoot and Knights, 1998) support traditional notions of masculinity that in turn help shape the MBA curriculum. Some organizations (e.g. IBM, Credit Suisse Group, BMW) have a direct influence on MBA pedagogy by requesting bespoke programmes that support their established business processes - which in most cases place emphasis on the above 'masculine' values (Chaker, 2006). This is further underpinned by accreditation bodies and funding agencies. The Association of MBAs (a body that accredits MBA programmes in the UK) for instance, requires students irrespective of their area of specialisation to cover six core and largely 'hard' business skill areas: marketing, business environment, accounting and quantitative methods, finance, organisational theory and information technology. A seventh core area - focusing on 'softer' management practices and processes - has only recently been given prominence and in response some business schools are now introducing soft skills to their programmes. Notable examples include Warwick (UK), SDA Bocconi School of Management (Milan) and Audencia Nantes School of Management (France) (Jackson, 2007). 
Furthermore, a number of scholars (e.g. Brookfield, 1994; Reynolds, 1999;

Antonacopolou, 1999) have identified that students (especially from Africa and Southeast Asia) prefer a traditional model of teaching and learning which emphasises teacher's expertise - leading to a prescriptive and deterministic approach - rather than critical analysis or dialogue. Financial constraints and the need to target high paying international students have also influenced pedagogy. As MacFarlane (1997) points out, demands particularly from international students for key functional 'hard' skills (finance, accounting, system analysis) - seen as practical, useful and judged positively by managerialist standards of relevance - are increasingly shaping the MBA. In this respect, Grey et al (1991) note that students who have been socialised to be instrumental about learning and academics that privilege this mode of teaching have both contributed to the masculine nature of MBA course design and delivery.

\section{Gender Differences in MBA Outcomes}

Much of the work on MBA outcomes has focussed on 'extrinsic' benefits such as career progress and pay and has highlighted the ways in which women are disadvantaged despite their MBA qualification. In this context, results suggest that women do not progress as far or receive the same level of remuneration as men. A recent report by Catalyst (Catalyst, 2000), for example, indicates that men tend to advance further than women in both line positions and reporting span and that men are significantly more likely than women to be satisfied with their career advancement after completion of their course. Looking at pay, Schneer and Reitman (1990; 1995) and Simpson $(1995 ; 1996 ; 2000 a)$ found that salary growth for women was significantly smaller than for men and that the gender gap in pay increased over time. This indicates that the MBA may not be as beneficial for women as men and has led 
to suggestions that programmes need to focus more on women's experiences and on meeting women's needs (Hilgert, 1998; Sinclair, 1997).

Other work, however, looking at 'intrinsic' benefits of confidence, credibility and the acquisition of interpersonal and communication skills, has found that it is women, rather than men, who reap the full rewards from the MBA. Such work (e.g. Simpson, 1995; 1996; 2000b; Simpson et al, 2005; Sturges et al. 2003) suggests that while men place emphasis on the credential value of the qualification in enhancing mobility and marketability and while both men and women benefit from a new 'skill set', women in particular value the MBA experience in terms of how it changes their perceptions and attitudes so that they see themselves, their colleagues and their organizations differently as a result of the course. In a UK based study of MBA outcomes, Simpson for example found that women enjoyed "a process of self discovery, an 'eye-opening' experience that (brought) a new awareness of themselves, and of the processes and practices that (were) occurring around them" (Simpson, 2000b: 776). While acknowledging the significance of gender differences in styles of speaking (Tannen, 1991), which may mean a greater reluctance on the part of men to discuss issues around personal change and feelings, the study found no evidence of such 'transformations' among men.

A subsequent Canadian based survey (Simpson et al., 2005; Sturges et al, 2003) highlighted a similar trend. While both men and women in the study gained confidence from the course, for women the change was more fundamental. Men gained confidence from the acquisition of identifiable 'hard' skills such as data analysis and financial management while women in addition to this found confidence 
through personal development - in particular through feelings of achievement, greater self worth and a sense of empowerment. Women redrew their 'mental boundaries' of what they considered achievable, had greater understandings of self and others and the relationship between them and developed skills of listening, speaking and, significantly, being heard. They became more assertive, developed greater self worth and no longer assumed that colleagues' and line managers' knowledge and judgement were superior to their own. They performed confidently at meetings and were able to 'speak up' to power - all of which were seen to have a major impact on their effectiveness at work and the quality of their interpersonal working relationships.

In other words, the MBA led to profound changes in how women saw themselves and others and how they acted out their professional and managerial roles. Similar themes of transformation run through Hilgert's (1998) study of six women graduates from an executive MBA programme where the MBA experience was associated with "broadening impacts" in terms of new understandings of the world and life-changing developmental outcomes. Evidence from these studies therefore point to the transformative nature of the MBA experience for women as their earlier 'understandings' are challenged and ultimately change. In this context, as Simpson (2000a; 2000b) argues, there was less evidence of transformative change for men.

\section{Transformations and Learning}

Overall, this suggests that gender differences exist in the outcomes from the MBA. Men are likely to gain more in career terms through higher pay and managerial status, placing value on enhanced marketability and 'hard' skills from the course. For women, however, the MBA may be more 'transformative' in that it contributes 
towards a critical awareness and a fundamental shift in assumptions and attitudes that lead, in turn, to new understandings of themselves and of their (organizational) world.

Themes of 'transformation' run through many accounts of organizational and individual learning. These suggest in different ways that higher level (Fiol and Lyles, 1985), deep (Marton and Saljo, 1984; Brown, 2000), reflective (Jarvis, 1987; 1992) double loop (Argyris and Schon, 1974) or transformative (Appelbaum and Goransson, 1997) learning can be distinguished from that which is 'lower level', 'surface', 'unreflective', 'single loop' or 'incremental'. In single loop learning (Argyris and Schon, 1974), for example, we learn to adjust our behaviour whilst adhering to existing assumptions and values whilst double loop learning leads us to challenge those values. Similarly, reflective learning (Jarvis, Holford and Griffin, 2005; Jarvis, 1987 ; 1992) involves critical scrutiny of the context and/or the knowledge being presented and the subsequent decision to accept or change that context or knowledge. While there are conceptual differences between these approaches, they share common ground in that the former concepts capture more fundamental changes for the individual or organization. In contrast to those categories of 'lower level' learning which place emphasis on incremental change and on practical, adaptive or routine processes, higher level learning typically encompass shifts in core assumptions or frames of reference which redefine 'mental modes' (Appelbaum and Goransson, 1997; Senge, 1990) or 'theories for action' (Argyris and Schon, 1974) and which involve profound changes in self and in 'somatic emotional dimensions' (Cope, 2003). In other words, such learning is transformative in that it generates new understandings and, as Cope suggests, forces individuals to question, in ways similar 
to those suggested by CME, established ways of working and to develop new discursive and behavioural strategies.

Much of the work on transformative and associated learning draws links between this learning level and exposure to challenging 'learning episodes' (Rae and Carswell cited in Cope, 2003). Appelbaum and Goransson (1997) and Daudelin (1996) for example, argue that learning from unusual events can be transformative as new thought processes are required. Similarly, Mezirow $(1990 ; 1991)$ links transformative learning to 'disorienting dilemmas' and argues that crises and challenges can become the catalyst for changes in self perception and for critical reflection. Furthermore, transformations through learning can be cumulative and lead to greater transformations through awareness of constraining assumptions and "emancipation from perceived constraints" (Collin, 1996).

In this context, the MBA experience may well set the stage for a challenging 'learning episode', capable of providing the conditions necessary for the type of changes discussed earlier in this paper. Such changes, in that they involve a challenge to existing attitudes and values as well as a potential for the emancipation of others and of self, has a strong alignment with the aims of CME as set out above. On this basis, women may be, through the type of reflexive awareness proposed by CME, be experiencing some of the 'transformations' as outlined by Mezirow $(1990 ; 1991)$ and others in the field . Evidence indicates that women do develop 'new understandings' of the world and that they experience a shift in the assumptions they have held about themselves and others. This leads, in turn, to different ways of working and of managing their relationships at work. However, as Simpson (2000b) suggests, the 
'broadening' of the individual and 'life changing developments' could be eluding men.

\section{The Masculinity of the MBA and the 'Un-development' of Men}

A contradictory relationship might therefore exist between the gendered nature of the

MBA and the outcomes for men and women. More specifically, while the MBA has been shown to incorporate a masculine bias in terms of course culture, course content and core values, men may not necessary gain full advantage from being privileged in this way. The programme may well favour male interests and reflect male values in its organization and approach (Sinclair, 1997), but it could be men, rather than women, who are 'undeveloped' as a result. By contrast, despite a neglect of women's voices and an antipathy towards the 'feminine', it may be women rather than men who experience 'higher level' learning and an 'opening of vision' (Chia, 1996) from the course. On this basis it could be argued that it is men, rather than women, who are 'under-developed' by the MBA.

There are several possible explanations for this apparent contradiction. One possibility is that the MBA may pose a greater challenge for women. As briefly outlined above, recent work (e.g. Daudelin, 1996; Appelbaum and Goransson, 1997; Cope, 2003) has highlighted the importance of challenges as rich sources of learning as heightened attention and experimentation encourage new understandings. Similarly, Ohlott, Ruderman and McCauley (1994) suggest that meeting challenges and overcoming obstacles can be a powerful developmental and affirming experience and that women in particular, because of the difficulties they face in the workplace, often benefit in this way. In the context of the MBA, conquering lack of self 
confidence and coping with pressures and demands from the course itself, as well as from possible feelings of alienation and marginalisation, may intensify feelings of success and create the conditions for more fundamental change. In support of this a language of challenge and change runs through many women's accounts of their MBA experience (see Sinclair, 1997; Hilgert, 1998; Simpson, 2000b; Simpson et al, 2005).

A further challenge concerns the implications of managing the possible tension between the dominant 'male' culture of the MBA and women's outlook and experiences. In this respect, the MBA may act as a 'critical disorienting dilemma' (Mezirow, 1990; 1991) capable of triggering powerful transformative learning, as women's 'understandings' collide with dominant discourses within the MBA. For example, several women in Simpson et al's (2005) study claimed they had become "more objective" "less emotional" "more detached" and had "toughened up" as a result of their MBA, possibly because they were adjusting to and assimilating more 'masculine' attitudes and practices prevalent on the course. This new approach was seen to be beneficial when difficult decisions had to be made.

Through this tension (between dominant masculine discourses and their own attitudes and values), women may therefore be encouraged to shed old constraining assumptions and embrace new ways of thinking and doing. As Simpson (2000b) argues, by reflecting dominant 'masculine' values, the MBA may not provide the same opportunity for men. If the MBA fails to challenge men's outlooks and perceptions, then they may well emerge from the programme with their understandings largely intact. In other words, because their assumptions and values 
are supported and reinforced by the MBA culture around them, men may be less likely to develop powers of reflection or re-assess existing mindsets - factors which as Appelbaum and Goransson (1997) and writers within CME suggest (e.g. Grey, 2002; 2004), form key ingredients for deeper 'transformative' learning and emancipatory change.

Furthermore, the experience of being in the minority may cultivate among women a consciousness about the politics of self and wider organizational practices which, as Sinclair (1997) suggests, those situated in the mainstream may be slower or more resistant to understand. Women may therefore be more 'tuned in' to underlying processes that largely elude men. For example, Simpson et al's (2005) study of Canadian MBAs found that women were acutely aware of the ways in which their voices and interests were silenced, both in their employing organizations and in the MBA. In this respect, the gaining of a 'voice' through the MBA and the new found ability to 'speak and be heard' were both enlightening and empowering, the results of which were carried into more effective relationships and communications at work. The dominant, however, are rarely the subject of scrutiny (Hearn, 1996) and, by reason of their closeness to core values and practices, are less aware of, and as Sinclair (1997) suggests, often resistant to the implications of underlying processes of power and privilege. This was highlighted in Sinclair's account of her experiences introducing a focus on constructions of masculinities to a management development programme (Sinclair, 2000). In this context, managers displayed a resistance to the critical appraisal of their own power and privilege, preferring to focus on the 'Other' (e.g. women, ethnic minority groups) as the source of diverse organizational problems. However, as Hearn (1996) argues, understanding management as a social 
practice requires a critical appraisal (a 'de-construction') of the dominant. This can open up new understandings of organizational practices and processes as well develop powers of imagination and reflection. In this context, as Sinclair (1997) suggests, listening to the experiences of those on the margins can "illuminate aspects which are taken for granted by those who are more comfortably embraced within the dominant culture" (Sinclair, 1997: 314). That comfortable position, however, may mean that men miss out on challenges and tensions which successfully propel women into new thought processes and strategies for action.

\section{A Critical Feminisation of the MBA}

This suggests a need to 'feminise' the MBA to create a more comfortable environment for women and to encourage a richer level of learning and more possibilities for 'transformations' among men. As stated earlier, a feminization does not necessarily entail the wholesale rejection of the masculine but can be used in a 'critical context' (Due Billing and Alvesson, 2000) by creating the possibility of alternative orientations. There are, as Knights and Kerfoot (2004) have pointed out, advantages that accrue from 'masculine' practices and values - and, as has been argued elsewhere (Simpson, 2006), the benefits gained by women from the MBA, despite its masculine foundations, may be testimony to this effect. Rather than a rejection of masculine values and practices and a replacement by the feminine, critical feminization would help position alternative orientations and, through critical awareness and reflexivity advocated by CME, challenge the dominance of certain ideas by reflecting on the conditions that support their privilege.

This entails going beyond simple prescriptions that involve an increase in numbers of women (on the basis that critical mass may facilitate the inclusion of women's voices 
and values), or the introduction of 'softer' skills to MBA programmes such as the development of personal, interpersonal and process abilities - largely associated with (feminine) emotions, imagination and creativity. More fundamentally, a shift towards a 'feminised' MBA would involve, from the perspective of CME, a critical appreciation of the context of management education and practice. Rather than prioritising a 'systems' approach to management, this perspective would highlight the social and political dimension of managerial work (Watson, 2001). The power relations involved in management and its practices would be a central focus here. As Sinclair (2000) argues, there is a value in helping managers develop an understanding of how asymmetric power and the privileging of masculinity shapes organizational experiences. Placing the centre in the sights of scrutiny can encourage managers to reflect on dominant practices and strategies as well as on their own contributions to the perpetuation of the effects.

Such discussions may be difficult because, as Sinclair suggests, language and power interact to help the dominant values remain invisible. However, such difficulties may be ameliorated through the appropriation of students' reflective capacities as an active teaching resource (Cunliffe et al, 2002) or through the use of negotiated narratives (Watson, 2001) which encourage students to reflect critically on the power of discourse in framing meanings and understandings. In so doing, students not only develop critical reflection and become aware of the broader implications of their decisions but also, by appreciating the frames of reference within which decisions are made, can more easily step outside those boundaries and 'think outside the box', key attributes of 'higher' level or 'transformative' learning as well as a necessary 
precondition for managers who need to be creative and innovative in a rapidly changing world.

\section{Conclusion}

This paper set out to explore the masculinity of the MBA and different ways men and women benefit from the course. It has been argued that while CME has explored the moral and political foundations of management education, it has overlooked the masculine bias within the MBA. The masculine nature of the MBA experience has been analysed by focusing on the values of masculinity that permeate pedagogies through the dominance of gendered discourses of managerialism and rationality that go beyond implications of numerical balance of men and women or a relative focus on skills. In so doing, it has highlighted a possible link between the masculine ethos underpinning the course and the 'un-development' of men.

As we have seen, this contradiction may well be located in the lack of challenge posed to men's assumptions and values which, because of the tension between discourses of femininity and the MBA, may open up richer learning possibilities for women and lead to greater opportunity for 'transformative' change. While recognising the possibility of other influencing factors (e.g. gender differences in styles of speaking and/or expressions of feelings), the nature of this contradiction can have far-reaching implications for both management education and management practice. As we have seen, the unreflective reproduction of masculine values and ways of working as well as an over-focus on 'hard' analytical skills not only create a 'chilly' learning environment for women but may also limit the growth potential for men. Moreover, if 
men are emerging from their MBA with attitudes and values largely intact and with a limited awareness of social and political cultures around them, then there are likely implications for the quality and appropriateness of their decisions and practices. Financial pressures and the demands of students, staff and accreditation bodies may well mitigate against radical programmatic change. However, a central argument of this paper points to the necessity for a greater infusion of 'critical feminization' into the MBA. While CME has largely ignored the implications of the gendered nature of the MBA, a feminization as outlined above is very much in accordance with its aims and principles. In short, if it is to avoid being mired in an outdated and sexist pedagogy and in order to fulfil the learning potential of both men and women so as to encourage a 'transformation' into reflective managers, there needs to be a 'critical feminization' of the MBA. 


\section{REFERENCES}

Alvesson, M. and Willmott, H. (1992) Critical Management Studies, London: Sage.

Alvesson, M. (1998) 'Gender Relations and Identity at Work: A Case Study of Masculnities and Femininities in an Advertising Agency'. Human Relations, Vol.51 No.8, pp.969-1006.

AMBA (2004) Annual Report. London: Association of MBAs.

Antonacopoulou, E. P. (1999) 'Teaching 'Critical Thinking' to MBAs: The contribution of critical thinking to Management Learning'. Proceedings of the 1 st International Critical Management Studies Conference. UMIST, Manchester.

Appelbaum, S. and Goransson, L. (1997) 'Transformational and Adaptiver Learning within the Learning Organization: A Framework for Research and Application', The Learning Organization, Vol.4, No. 3, pp. 115-28.

Argyris, C. and Schon, D. (1987) Organizational Learning: A Theory of Action Perspective, San Francisco, CA: Jossey Bass.

Arthur, M. and Rousseau, D. (1996) in Arthur, M. and Rousseau, D. (Ed.), The Boundaryless Career:A New Employment Principle for a New Organizational Era. New York: Oxford University Press.

Simpson, R. and Sturges, J. (2004) Masculinity and Management Education: Feminising the MBA, paper presnted at the British Academy of Management Conference, St Andrrews, Sept.

Simpson (1995) 'Is Management Education on the Right Track for Women?' Women in Management Review, Vol. 10, No. 6, pp.3-8.

Simpson, R. (1996) Does an MBA Help Women? Gender Work and Organisation, Vol.3, No.2, pp.115-121.

Simpson, R. (2000a) 'Winners and Losers: Who Benefits Most from the MBA'. Management Learning, Vol.31, No.2, pp.331-352.

Simpson, R. (2000b) 'A Voyage of Discovery or a Fast Track to Success: Men, Women and the MBA'. Journal of Management Development, Vol.19, No.9, pp. 764782.

Simpson, R. (2006) 'Masculinity and Managememt Education: Feminizing the MBA', Academy of Management Learning and Education, Vol. 5, No. 2, pp. 182-193. 
Simpson, R. Sturges, J., Woods, A. and Altman, Y. (2005) 'Gender Age and the MBA: An Analysis of Extrinsic and Intrinsic Career Benefits', Journal of Management Education, Vol. 29, No.2, pp. 218 - 247.

Beatty, J. (2004) 'Grades as Money and the Role of the Market Metaphor in Management Education', Academy of Management Learning and Education, Vol. 3, No.2, pp.187-196.

Bologh, R. (1990) Love or Greatness: Max Weber and Masculine Thinking - A Feminist Enquiry, London: Unwin Hyman.

Brooks, A. and Mackinnon, A. (2001) Gender and the Restructured University, Open University Press.

Brown, R. (2000) 'Contemplating the Emotional Component of Learning', Management Learning, Vol.31, No.3, pp. 275-93.

Brookfield, S.D. (1994) 'From the Dark Side: A Phenomenography of Adult Critical Reflection". International Journal of Lifelong Education, Vol. 13, No.3, pp. 203-218.

Burke, R. and McKeen, C. (1994) 'Career Development among Managerial and Professional Women'. In M. Davidson and R. Burke (Ed.) Women in Management: Current Research Issues, London: Chapman.

Business Week. (2000). Ranking Global Programs 54, Oct 2.

Catalyst (2000) Women and the MBA: Gateway to Opportunity New York: Catalyst.

Chaker, A.M. (2006) 'Company design, fund curricula at universities', The Wall Street Journal, September, 11.

Chia, R. (1996) Teaching Paradigm Shifting in Management Education: University Business Schools and the Entrepreneurial Imagination, Journal of Management Studies, Vol. 33, No.4, pp.409-428.

Clarke, M. (1999) Management Development as a Game of Meaningless Outcomes. Human Rersource Management Journal, Vol. 9, No.2, pp.38-49.

Collin, A. (1996) 'The MBA: The potential for Students to Find their Voice in Babel'. In R. French and C. Grey (Ed.), Rethinking Management Education, London: Sage.

Collinson, D. and Hearn, J. (1994). 'Naming Men as Men: Implications for Work, Organization and Management'. Gender Work and Organization, Vol.1, No1, pp. 220.

Connell, R. (1995) Masculinities', University of California Press.

Connell, R. (2000) The Men and the Boys, Cambridge: Polity Press. 
Cope, J. (2003) Entrepreneurial Learning and Critical Reflection: Discontinuous Events as Triggers for 'Higher-level' Learning, Management Learning Vol. 34, No.4, pp.429-450.

Cunliffe, A., Foray, J. and Knights, D. (2002) 'Considering Management Education'. Journal of Management Education, Vol. 26, No.5, pp.489-495.

Currie, G., and Knights, D. (2003) "Reflecting on a Critical Pedagogy in MBA Education", Management Learning, Vol.34, No.1, pp.27-49.

Daudelin, M. (1996) 'Learning from Experience through Reflection', Organziational Dynamics, Vol. 24, No.3, pp. 36-48.

Due Billing, Y. and Alvesson, M. (2000) 'Questioning the Notion of Feminine Leadership: A Critical Perspective on the Gender Labelling of Leadership'. Gender Work and Organization, Vol.7, No.3., pp.144-158.

Fiol, C. and Lyles, M. (1985) 'Organizational Learning', Academy of Management Review, Vol. 10, No. 4., pp. 803-13.

Fondas, N. (1996) 'Feminization at Work: Career Implications'. In Arthur, M. and Rousseau, D. (Ed.), The Boundaryless Career, New York: Oxford University Press.

French, R. and Grey, C. (1996) 'Rethinking Management Education: An Introduction', in French, R. and Grey, C. (Eds.), Rethinking Management Education, London: Sage.

Grey, C. and Mitev, N. (1995) 'Management Education: A Polemic'. Management Learning, Vol. 29, No.1, pp. 73-90.

Grey, C., Knights, D. and Willmott, H.C. (1991) 'Beyond Positive Knowledge: Towards a Critical Management Pedagogy', paper delivered at the Management in an Academic Context Conference, University of Uppsala, Sweden.

Knights, D. and Willmott, H. (1996) 'Is a Critical Pedagogy of Management Possible', in R. French and C. Grey (Eds.), Rethinking Management Education, London: Sage.

Grey, C. (2002) 'What are Business Schools For?' Journal of Management Education, Vol. 26, No.5, pp.496-511.

Grey, C. (2004) 'Reinventing Business Schools: The Contribution of Critical Management Education'. Academy of Management Learning and Development, Vol. 3, No.2, pp.178-187.

Hearn, J. (1994) 'Changing Men and Changing Management:Social Change, Social Research and Social Action. In M. Davidson and R. Burke (Eds.), Women in management: current research issues. London:Paul Chapman. 
Hearn, J. (1996) 'Deconstructing the Dominant: Making the One(s) the Other(s)', Organization, Vol. 3, No.4, pp. 611-626.

Hilgert, A. (1998) 'Professional Development of Women and the MBA', Journal of Management Development, Vol. 17, No. 9, pp.629-643.

Hines, R, (1992) 'Accounting: Filling the Negative Space', Accounting Organization and Society, Vol.17, No 3-4, pp. 314-41.

Jackson, N. (2007) 'How do business schools keep up with what employers are looking for?' The Independent, $14^{\text {th }}$ June.

Jarvis, P. (1987) Adult Learning in the Social Context, Croom Helm, London.

Jarvis, P. (1992) Paradoxes of Learning, Jossey-Bass, San Francisco.

Jarvis, P., Holford, J. and Griffin, C. (2005) The Theory and Practice of Learning, London: Routledge.

Kanter, R. (1989) 'The New Managerial Work'. Harvard Business Review. Vol. 67, No. 6, pp. 85-92.

Kerfoot, D. and Knights, D. (1993) 'Management Masculinity and Manipulation: From Paternalism to Corporate Strategy in Financial Services in Britain'. Journal of Management Studies, Vol.30, No.4, pp.659-77.

Kerfoot, D. and Whitehead, S. (1998) 'Boy's own Stuff: Masculinity and the Management of Further Education’. The Sociological Review, Vol. 46, No.3, pp. 436537.

Kerfoot, D. and Knights, D. (1998) 'Managing Masculinity in Contemporary Organizational Life: A Man(agerial) Project', Organization, Vol. 5, no.1,pp.7-26.

Kilduff, M. and Mehra, A. (1996) Hegemonic Masculinity Among the Elite - Power, Identity, and Homophily in Social Networks. In Cheng, C. (Ed.), Masculinities in Organizations, London: Sage.

Knights, D. and McCabe, D. (2001) 'A different World: Shifting Masculinities in the Transition to Call Centres'. Organization, Vol. 8, No. 4, pp. 619-645.

Knights, D. and Kerfoot, D. (2004) 'Between Representations and Subjectivity: Gender Binaries and the Politics of Organizational Transformation'. Gender Work and Organization, Vol.11, No. 4, pp.432-454.

Lee, C. (1994) 'The Feminization of Management'. Training. November, 25-31. 
MacFarlane, B. (1997) 'The Business Studies First Degree: Institutional Trends and the Pedagogic Context. Teaching and Higher, Education, Vol 2 (1), 45-57.

Martin, G. and Butler, M. (2000) 'Comparing Managerial Careers, Management Development and Management Education in the UK and the USA: Some Theoretical and Practical Considerations'. International Journal for Training and Development, Vol.4, No.3, pp. 196-207.

Marton, F. and Saljo, R. (1984) 'Approaches to Learning' in F. Marton, D. Hounsell and N. Entwistle (Eds) The Experience of Learning, Scottish Academic press, Edinburgh.

Mavin, S., and Bryans, P. (1999) Gender on the agenda in management education?

Women in Management Review, Vol. 14, No.3, pp. 99-104.

Mezirow, J. (1990) 'How Critical Reflection Triggers Transformative Learning' in J. M. Associates (eds) Fostering Critical Reflection in Adulthood: A Guide to Transformative and Emancipatory Learning. San Francisco, CA. Jossey-Bass.

Mezirow, J. (1991) Transformative Dimensions of Adult Learning. San Francisco, CA: Jossey-Bass.

Mintzberg, H. and Gosling, J. (2002) 'Reality Programming for MBAs'. Strategy and Business, 26 (1): 28-31.

Morgan, D. (1996) 'The Gender of Bureaucracy'. In Collinson, D. and Hearn, J. (Eds.), Men as Managers and Managers as Men, pp 46-60. London: Sage.

Ohlott, P., Ruderman, M. and McCauley, C. (1994) 'Gender Differences in Managers' Developmental Job Experiences', Academy of Management Journal. Vol. 37, No.1, pp. 46-67.

Perriton, L. and Reynolds, M. (2004) Critical Management Education: From Pedagogy of Possibility to Pedagogy of Refusal'. Management Learning, Vol.35, No.1, pp. 61-77.

Pfeffer, J. and Fong, C.(2002) 'The End of Business Schools? Less Success than Meets the Eye', Academy of Management Learning and Education, Vol.1, No.1, pp.78-95.

Porter, L. and McKibbin (1988) Management Education and Development: Drift or Thrust into the $21^{\text {st }}$ Century. New York: McGraw Hill.

Rae, D. and Carswell, M. (2000) 'Using Life-story Approach in Researching Entrepreneurial Learning: The Development of a Conceptual Model of and its Implications in the Design of Learning Experiences', Education and Training, Vol. 42, Vol.4/5,pp. 220-7.

Reynolds, M. (1999), "Grasping the nettle: possibilities and pitfalls of a critical management pedagogy", British Journal of Management, Vol. 9, No.2, pp.171-84. 
Roberts, J. (1996). 'Management Education and the Limits of Technical Rationality'. In French, R. and Grey, C. (Eds.), Rethinking Management Education, London Sage: $17-36$.

Ross-Smith, A. and Kornberger, M. (2004). 'Gendered Rationality: A Genealogical Exploration of the Philosophical and Sociological Conceptions of Rationality, Masculinity and Organization'. Gender Work and Organization, 11 (3): 280-305.

Schneer, J. and Reitman, F. (1990). 'Effects of Employment Gaps on the Careers of Schein, V. E. (2001). A global look at psychological barriers to women's progress in management. Journal of Social Issues, Vol. 5, No. 4, 675-688.

MBAs: More Damaging for Men than Women?' Academy of Management Journal, Vol. 3, No.2, pp. 392-406.

Schneer, J. and Reitman, F. (1995) 'The impact of gender as managerial careers unfold', Journal of Vocational Behaviour, Vol.51, pp. 411-434.

Senge, P. (1990) 'The Fifth Discpline: The Art and Practice of the Learning Organization', London: Century Business.

Sinclair, A. (1995) 'Sex and the MBA'. Organization, Vol. 2, No 2, pp. 295 - 317.

Sinclair, A. (1997) 'The MBA through Women's Eyes: Learning and Pedagogy in Management Education', Management Learning, Vol. 28, No.3, pp.313-330.

Sinclair, A. (2000) 'Teaching Managers about Masculinities: Are you Kidding?' Management Learning, Vol.31, No.1, pp. 83-103.

Sturges, J., Simpson and Altman, Y. (2003). 'Capitalising on Learning: An Exploration of the MBA as a Vehicle for Developing Career Competencies'. International Journal of Training and Development, 7 (1), 53-67.

Smith, C. (1997) 'Gender Issues in Management Education: A New Teaching Resource', Women in Management Review, Vol.12, No.5, pp.100-4.

Smith, C. (1998) 'Best Practice in Management Education: Capitalising on Gender Diversity Awareness', Journal of Management Development, Vol. 17, No.1, pp.6-16

Tannen, D. (1991) You Just Don't Understand, London: Virago.

Thomson, A., Maybe,C., Storey, J., Gray, C. and Iles. P. (2000) Changing Patterns of Management Development, Oxford: Blackwell.

Watson, S.R. (1993) 'The Place for Universities in Mangement Education', Journal of General Management, Vol,19, No.2, pp.14-42. 
Watson, T. (2001) 'Beyond Managism: Negotiated Narratives and Critical Management Education in Practice'. British Journal of Management, Vol.12, No.4, pp. 385-396.

Weick, K., Mintzberg, H. and Senge, P. (1999). Transforming Management Education for the $21^{\text {st }}$ Century, Symposium conducted at the Annual Conference for the Academy of Management, Chicago.

Willmott, H. (1994) 'Management Education: Provocation to a Debate', Management Learning, Vol. 25, No.1, pp.105-36. 